\title{
Have the changes introduced by the 2004 Higher Education Act made higher education admissions in England wider and fairer?
}

Neil Harrison, University of the West of England

Abstract : 'Widening participation' and 'fair access' have been contested policy areas in English higher education since at least the early 1990s. They were key facets of the 2003 White Paper The Future of Higher Education and the subsequent 2004 Higher Education Act, with stated objectives that the reach of higher education should be wider and fairer. In particular, there has been considerable concern about admissions to 'top universities', which have remained socially-exclusive as well as academically-exclusive. The principal policy tools used by the Act were the introduction of variable tuition fees, expanded student grants, discretionary bursaries and the new Office for Fair Access (OFFA).

This paper draws on publicly-available statistics to assess whether the changes implemented by the 2004 Act have indeed made access to English higher education wider and fairer in relation to young people progressing from state schools and colleges and from lower socio-economic groups. It concludes that, while there is some evidence for modest improvements, these have been concentrated outside the 'top universities', which have seen slippage relative to the rest of the sector. The paper concludes with a discussion of the reasons why financial inducements appear to be a flawed and naive approach to influencing student demand.

Keywords : higher education, widening participation, fair access, social class, students, tuition fees 


\section{Historical context}

Access to higher education in England ${ }^{1}$ has been a public policy concern since at least the 1960 s, when financial incentives were introduced to encourage applications from less affluent households (Anderson 1960; Robbins 1963). When steps were taken in the late 1980s and early 1990s to reduce the financial support offered to students, it was feared (Stephens 1990; Harris 1991) that this could lead to a drop in participation from students from lower socio-economic groups. These fears were not realised; higher education was expanding, bringing an increase in participation from all social groups. By 1995, the proportion of young people from manual backgrounds entering higher education was 15 percent, compared to 4 percent in 1960 ( $\mathrm{NClHE}$ 1997). Even in 1998, when tuition fees of $£ 1,000$ were charged for the first time, admissions from under-represented sections of society continued to rise (NAO 2002). In 2008, the participation rate for those from lower socio-economic groups stood at 21 percent $^{2}$ (DBIS 2009). Despite these increases in participation, there is continuing concern about a 'social class gap', where "people from lower socio-economic backgrounds make up around one half of the population of England, but represent just 29 per cent of young, full-time, first entrants to higher education" (NAO 2008, 6). The 'widening participation' agenda has been extremely prominent in the 2000s, with an estimated $f 392 \mathrm{~m}$ currently invested annually from the public purse into recruiting and supporting students from groups that are under-represented in higher education (NAO 2008).

While one focus has been on widening participation, a parallel policy concern about 'fair access' to 'top universities' has also received significant attention. This issue has centred on the imbalance

\footnotetext{
${ }^{1}$ England will be examined in this paper as distinct from the whole United Kingdom because (a) the financial support systems in Wales, Scotland and Northern Ireland differ, and (b) the location-adjusted benchmarks for widening participation performance (see below) are only calculated and published for England.

${ }^{2}$ The definitions of lower socio-economic groups has changed significantly in the early 2000s (from the Registrar General's system to the National Statistics Socio-Economic Classification), but this figure represents the closest corollary of the measure used from the 1960s to the 1990 s.
} 
of admissions between institutions, in the wake of the integration of polytechnics and colleges into a single higher education sector in 1992. Broadly speaking, those institutions with the most rigorous entry requirements drew their student body from private schools and middle class households, while those that catered for low ability levels tended to recruit more heavily from state-funded schools, further education colleges, minority ethnic communities and working class households (Ainley 1994; Modood and Shiner 1994; NCIHE 1997).

The political agenda of the late 1990s and early 2000s was thus twofold: to increase the proportion of students drawn from lower socio-economic groups and to work towards a more equitable demographic distribution within the sector. Components have included the government-funded Aimhigher initiative to raise aspirations among schoolchildren (DfES 2003), a major review of admissions practices (Schwartz 2004), targeted additional financial support (DfEE 2000), institutional outreach work and other approaches designed to break down real and perceived 'barriers' (NAO 2002; Universities UK 2005; Gorard et al. 2007).

This paper will analyse the impact of the 2004 Higher Education Act on the fair access and widening participation agenda, investigating the policy levers used by the Government and their effect on entry to higher education, especially to the highest status universities ${ }^{3}$.

\section{The 2004 Higher Education Act and after}

Despite this policy interest in widening participation and fair access, higher education in England in the 2000s continued to be highly stratified, with institutions pursuing strongly contrasting missions

\footnotetext{
${ }^{3}$ To avoid clumsy phraseology, the term 'university' will be used in this paper to mean any institution offering higher education, including colleges of higher education and further education colleges providing higher education courses.
} 
and attracting very different student populations, both in terms of attainment at 18 and demographic background. The 'Russell Group' of universities occupies what is perceived as the top position within this hierarchy, typified by large civic institutions with a strong research basis, very taxing entry requirements and a high demand for each available place. There are currently 16 Russell Group universities in England ${ }^{4}$, comprising around 13 percent of the higher education institutions and accounting for 25 percent of the full-time young first degree population. The Russell Group has no official status (it is a closed membership organisation), but it exerts considerable influence on government policy by dint of its market share, reputation for excellence, lobbying power and prestigious alumni.

The Russell Group institutions' reputation for excellence, however, does not extend to their performance in social inclusivity. Concern has long been voiced that 'top universities', as typified by the Russell Group, are socially-exclusive as well as academically-exclusive. The Dearing Report (NCIHE 1997) noted the demographic differences between the former polytechnics and older universities. These were drawn into even sharper focus by a series of reports by the Sutton Trust, which found that "the chance of getting into a top 13 university is approximately 25 times greater if you come from an independent school than from a lower social class or live in a poor area and is about double what it should be" (Sutton Trust 2000, 1). They later referred to the "missing 3,000" who are "a potential waste of talent" because they attend lower status universities than they might (Sutton Trust 2004, 1). While these reports did serve to make clear the stark differences in social mix between the various tiers of the higher education hierarchy, they focused on the admissions procedures and the approach of universities without seeking to understand the deeper social and cultural processes and individual choices which underpin student demand for higher

\footnotetext{
${ }^{4}$ The current English Russell Group members are: Birmingham, Bristol, Cambridge, Imperial College, Kings College London, Leeds, Liverpool, London School of Economics, Manchester, Newcastle-upon-Tyne, Oxford, Sheffield, Southampton, University College London and Warwick.
} 
education. They were also founded on an elitist agenda which presupposed that the top universities' offer the courses which are best suited to the most talented young people, underplaying the very high quality provision that exists in other universities, especially in specialised and vocational areas, as well as the role of individual preferences.

The fair access theme was picked up and partly challenged in contemporary governmental documents, which found that "the very significant differences in patterns of application are the main cause of differential access to universities, while admission procedures appear to be far less significant" (DfES 2003a, 12). In other words, it suggested that it was not that higher status universities purposefully discriminated against applicants from lower socio-economic groups or state schools, but that these people were far less likely to apply, even when they had attained the highest levels of pre-entry qualifications. Top universities were challenged to "understand why it is that students may be put off from applying to their institution" and to actively "encourage a broader range of applications" (DfES 2003a, 13). There is a key tension here with the Sutton Trust position, as outlined above.

Steering a careful path through these contrasting perspectives, the 2003 White Paper, The Future of Higher Education, effectively skirted around the issue. On one hand, it asserted that "Education must be a force for opportunity and social justice, not for the entrenchment of privilege" (DfES 2003b, 67), promoting efforts made by a number of Russell Group members to ensure "fair access" for "non-traditional students" by using transparent and holistic admissions procedures. On the other hand, it failed to challenge the status quo which led to the social segmentation within higher education, pushing the widening participation agenda towards lower status institutions with the creation of two-year foundation degrees (Jones and Thomas 2005). 
The resulting independent report into university admissions (Schwartz 2004) sought to establish five principles that underpin fair access: transparency; ability to select by achievements and potential; reliability and validity; minimisation of barriers; and, a professional approach. It concluded that the system was "generally fair" with "room for improvement" (ibid., 4). Among the suggestions were approaches that acknowledged the different educational origins of students, concluding that seeking "latent talent and potential, which may not fully be demonstrated by examination results, is a legitimate aim for universities and colleges which seek to recruit the best possible students" (ibid., 5). This egalitarian position was somewhat undermined by the addition of the three words: "regardless of background". In other words, the applicant's background was to be disregarded. Schwartz therefore stopped short of a more radical approach to address fairness of access, encouraging the greater use of contextual information, but leaving individual institutions to formulate their own admissions policies and steering them away from using "bias" to socially engineer their student mix. It is difficult to see, given the comments quoted above from The Future of Higher Education (DfES, 2003b), how this would significantly impact on fairness; patterns in application would continue to cause differential access.

Given these various policy contexts, there was significant unease surrounding the 2003 White Paper and the eventual passage of the 2004 Higher Education Act. Academics, commentators and politicians (e.g. Sanders and Goddard 2003; NatWest Bank 2005; Callender and Jackson 2005) saw a strong danger that the partial deregulation of tuition fees would discourage students from under-represented groups from seeking entry to higher education, particularly to Russell Group universities which were widely expected to charge the highest possible tuition fees $(£ 3,000$ per year ${ }^{5}$ ). The initial signs were that this was indeed the case (Lipsett 2005). The Government sought to offset these dangers by offering large grants (up to $£ 2,700$ per year) to students from low

\footnotetext{
${ }^{5}$ The figures provided for tuition fees, grants and bursaries are for the 2006/07 academic year and have risen in line with inflation since.
} 
income households, allowing the payment of fees to be deferred through a loan and increasing the post-graduation income threshold for loan repayments (DfES 2003b). This was coupled with a new regulatory body, the Office for Fair Access (OFFA), which was conceived to "commit universities to increase the take up of university places from the most disadvantaged groups" (DfES $2003 \mathrm{~b}, 85$ ) through the requirement to produce formal Access Agreements, with the threat of financial penalties for those deemed not to be doing enough.

The Access Agreements were conceived in broadly two sections. The first would lay out the institution's outreach activities, while the second would describe their tuition fee policy and the concomitant response to the requirement on universities to reroute a proportion of their additional income into financial bursaries for students from lower-income households (DfES 2003b). The initial purpose of these new bursaries was "to ensure that no additional financial barriers to entry are created" (DfES 2003a, 20), with the prevailing concerns about participation and fairness being explicitly acknowledged in the Secretary of State's instruction letter to the first Director of Fair Access (Clarke 2004) and OFFA's subsequent guidance to institutions (OFFA 2004).

The aims of OFFA were variously laid out to be to "safeguard and promote access" and "to protect the poorest students", with the expectation of "the most [effort], in terms of outreach and financial support, from institutions whose records suggest that they have furthest to go in securing a diverse student body" (Clarke 2004). The OFFA mission, at its inception, was therefore both one of protecting the current admissions profile in terms of the social mix, but also to see progress on participation and access, especially from the 'top universities'. However, as McCaig and Adnett (2009) note, this stopped short of placing a requirement for specific improvements onto individual institutions, wherever they may have been in the hierarchy. For this reason, among others, OFFA has been repeatedly challenged for being light-touch and toothless (Thomson 2003; Baty 2004; 
Jones and Thomas 2005; Gill 2009) and its sanctions over universities have never been used (NAO 2008).

One intended consequence of the 2004 Higher Education Act was to create a market based on price competition for tuition fees. However, this policy objective was not realised, with nearly every institution charging the maximum amount of $£ 3,000$ from the outset. In contrast, it could be argued that a competitive market in bursaries has emerged, with a myriad of schemes being put in place by higher education providers to further their individual missions in the context of their Access Agreements. Widely different sums of money have been made available to students using widely different eligibility criteria. A conservative estimate is that 350 separate schemes came into existence, focusing on income, academic merit, geographical location, school type, disability, ethnicity and so on (Harrison, Baxter and Hatt 2007). Just under $f 100 m$ was dispersed in this way in 2006/07, accounting for around a quarter of the total additional tuition fee income.

Research by McCaig and Adnett (2009) has revealed a clear stratification within the market for income-contingent bursaries, with higher status universities (including the Russell Group) tending to offer roughly twice as much per student, on average, as lower status institutions (NAO 2008). However, because of their entry profile, the numbers of bursaries offered by top universities is relatively low, with lower status universities offering bursaries to a larger pool of students. McCaig and Adnett (2009) found that, contrary to the Secretary of State's expectations (Clarke 2004), there was no evidence that 'top universities' were investing more than those with an already diverse entry profile, although there was significant variation between institutions. Furthermore, they note that institutions have tended to reduce their expenditure on incomebased bursaries since 2008/09 in favour of scholarships based on merit, 'academic potential' or subjects which struggle to recruit. In a contrary view, Callender, Wilkinson and Hopkin (2009) 
have recently argued that bursaries have been particularly efficacious in widening access to Russell Group institutions, where students report that the bursary offer is influential in their decisionmaking processes.

At the end of the decade, widening participation and fair access continued to be key policy issues, and there were signs that positions had begun to harden, with more critical comment emerging about progress made by Russell Group universities. A National Audit Office report into widening participation found that with reference to sector-wide widening participation benchmarks (these will be explained in more detail below), "on average, Russell Group institutions performed significantly below their benchmarks, and [the former polytechnics] performed significantly above theirs" (NAO 2008, 20), leading to very different social mixes. The report of a governmentsponsored panel on access to the professions (PFAP 2009) also drew strong attention to the disparities between Russell Group and other institutions in terms of their entry profile and the implications for students' career prospects.

\section{Methodology}

This paper seeks to answer two research questions about the effects the 2004 Higher Education Act, including the student financial support changes and the inception of OFFA and Access Agreements. These issues lie at the heart of the widening participation and fair access agendas which have been recurrent policy themes for at least ten years. The particular questions are:

(a) To what extent has the Act helped to widen participation? This will be investigated through analysing two of the national widening participation performance indicators, which 
measure admissions of students from state-funded schools and colleges and from lower socio-economic groups.

(b) To what extent has the Act helped to promote fair access? This will be investigated through analysing the performance of the Russell Group universities on the same indicators relative to other institutions, with specific reference to nationally-calculated benchmarks.

These questions will be investigated through analysing the data published annually by the Higher Education Statistics Agency (HESA 2010). The dataset provides sector-wide performance indicators on widening participation for each of the institutions in England.

The particular dataset used here relates to young (aged under 21 on entry) full-time undergraduate students on their first degree course (i.e. it excludes sub-degree level courses). This subset comprises around two-thirds of the total full-time higher education entrants. This was selected in order to limit the possible confounding factors, such as differing financial support arrangements for older students and the creation and growth of foundation degrees, and to thereby offer a broadly homogenous population across the period of analysis. The timeframe used is the six academic years from $2003 / 04$ to $2008 / 09^{6}$ and the dataset refers to new entrants ${ }^{7}$.

Three widening participation performance indicators are published annually for each institution:

\footnotetext{
${ }^{6}$ In reality, data is only available for a subset of these years due to definitional changes which render year-on-year comparison impossible. For 2008/09, the method used to elicit social class data differs from previous years, while the construction of the benchmarks has also changed significantly. Where such problems exist, these are highlighted in the text.

${ }^{7}$ Full details of the definitions used in the dataset are available at http://www.hesa.ac.uk/index.php?option=com_content\&task=view\&id=1447\&Itemid=141
} 
1. The proportion of entrants coming from a state-maintained school or college (in contrast to fee-paying private schools). This indicator has been developed in response to concern that certain universities, such as the Russell Group institutions, attract a disproportionate number of their students from private schools. Across the sector, the proportion from state schools and colleges has risen from 86.1 percent in 2002/03 to 88.0 percent in 2008/09.

2. The proportion of entrants who have been assessed as coming from households in the National Statistics Socio-Economic Classification (NS-SEC) groups 4 to 7 . This assessment is based on the occupation of the parent with the highest earnings and NS-SEC groups 4 to 7 broadly reflect manual occupations. Young people from these households continue to be under-represented within higher education, although the proportions have risen from 28.2 percent in $2002 / 03$ to 29.4 percent in $2007 / 08$. Data for $2008 / 09$ is not comparable to previous years as a different question was used to collect information and this has led to significant skewing of the data for this year.

3. The proportion of entrants drawn from geographical areas which historically provide relatively few higher education students. The definition of 'low participation neighbourhoods' changed significantly in 2006/07, synchronous with the changes in student financial support (though, for statistical purposes, a sector-wide figure has been retrospectively calculated for 2005/06). This performance indicator is therefore of only limited use in this study. 
For the purposes of this study, the institutions in the HESA dataset have been divided into three groups representing: (a) the Russell Group institutions ${ }^{8}$, (b) a 'Pre-1992' group of institutions comprising those that had university status prior to 1992, and (c) an 'Other' group comprised of higher education institutions not falling into the other two groups, including those gaining university status since 1992, higher education colleges and small specialist colleges. The data has been analysed for the six year period $2003 / 04$ to $2008 / 09$, during which the new financial and regulatory regime announced in the 2004 Higher Education Act came into operation. The trends in the proportion of entrants who come from state schools and lower socio-economic groups have been analysed for each of the three groups so that the results can be compared.

\section{Findings}

The headline data for widening participation presented above therefore suggests that access to full-time degree-level courses in England for young students has become slightly wider overall since $2003 / 04$. By 2007/08, more young students from state schools and colleges and from lower socio-economic groups were attending such courses than five years previously; a trend that continued into 2008/09 for the former. Table 1 shows that this trend has not been consistent, however. While the overall pattern has been positive, there have been years of progress compared with the previous year (e.g. 2005/06) mixed with years of backsliding (e.g. 2004/05). Notably, the first year under the changes instituted by the 2004 Higher Education Act was a year of progress in widening participation terms, with improvements on all three performance indicators.

\footnotetext{
${ }^{8}$ Excluding Cambridge University, as this is missing data from 2005/06 which has an identifiable impact on the aggregated time series data. Overall, the pattern for Cambridge University over the period being examined has been a decline in the recruitment of under-represented groups of students. Its exclusion therefore makes the performance of the remainder of the Russell Group appear better than it would were Cambridge included.
} 
[Table 1 here]

To place these statistics in context, around $42 \%$ of the population are drawn from NS-SEC groups 4 to 7 , while an estimated $7-14 \%$ of young people attend private schools prior to their entry to university; no exact figures exist and the proportion with some experience of private education is doubtlessly higher than the proportion whose whole schooling has been via this method (Lockhart 2009).

We now turn to contrast the average entry profile of the Russell Group universities in England with the remainder of the English higher education sector, with reference to the proportion of students recruited (a) from state schools and colleges, and (b) from NS-SEC groups 4 to 7 . For this analysis, two comparator groups have been constructed.

The first is a 'Pre-1992' group of those institutions that had university status prior to 1992, which broadly form the stratum immediately below the Russell Group in terms of reputation. These are typically medium-sized institutions with a strong research base. 24 institutions are included in this group, comprising around $25 \%$ of the total student population (and therefore of a similar overall size as the Russell Group).

The second is an 'Other' group of higher education institutions composed of those which are not members of the Russell Group or the Pre-1992 group. This is a very heterogeneous group, dominated by the former polytechnics and colleges which became universities in 1992 or in the eighteen years since. It also includes a number of higher education colleges and small specialist 
colleges; this 'Other' group comprises around half of the contemporary higher education sector by student numbers.

In order to construct the average entry profile statistics for the Russell Group, Pre-1992 group and Other group presented below, the individual performance indicators for each institution were extracted from the HESA datasets and arithmetically weighted by the size of their entry cohort before being aggregated into either the Russell Group, Pre-1992 group or Other group average. This was undertaken for each of the six academic years, where data was available.

\section{$\underline{\text { A. State schools and colleges }}$}

The average percentages for entrance from state schools and colleges for the two groups are presented in Table 2 and Figure 1. The data shows that, after a brief dip in 2004/05, there has been a steady rate of improvement in all three groups, with the difference between the Russell Group and the English average growing slightly, demonstrating that the pace of improvement in this group is lower than in others. There is no significant change in the relative entry profiles between the groups in $2006 / 07$ compared to $2005 / 06$, which would be concurrent with the changes brought about by the 2004 Higher Education Act. This suggests that the implementation of the Act has not affected the proportion of students entering each group from state schools and colleges.

[Table 2 here]

[Figure 1 here] 


\section{B. NS-SEC groups 4 to 7}

An identical approach was taken with regard to the proportion of students recruited from lower socio-economic groups and this is presented in Table 3 and Figure 2.

[Table 3 here]

[Figure 2 here]

Once again, we find with this indicator that the gap between the Russell Group and English average has grown across the period in question, from 8.9 percent in 2003/04 to 10.4 percent in 2007/08. The proportion of students from these backgrounds recruited by Russell Group universities remained roughly constant at around 19 percent, while there were significant increases in 2005/06 and 2006/07 for both the Pre-1992 group and the Other group. It is notable that the rises for these groups occur either side of the key year of policy change rising from the 2004 Higher Education Act. In other words, these two groups experienced an increase in their proportions of students recruited from lower socio-economic groups across the point where tuition fees were increased and bursaries and Access Agreements were introduced, while there was no change for Russell Group institutions.

\section{$\underline{\text { C. Using the location adjusted benchmarks }}$}

The other tools for examining questions concerning widening participation and fair access are the performance indicator benchmarks published as part of the HESA data. For each of the three 
widening participation indicators, a complex calculation is undertaken by HESA to determine what the indicator might be expected to be, based on those features of each individual institution which are not components of the performance of the institution, specifically including the subject, qualification and age profiles of the student body'. 'Location adjusted' benchmarks that adjust for the geographical locations from which the student body is drawn are also published alongside the basic benchmarks. It is this latter benchmark which is referred to the analysis below. There was a significant change in methodology in 2008/09 concerning how entry qualifications were integrated into the benchmark calculation. This means that the benchmarks for $2008 / 09$ are not comparable with previous years, with Russell Group institutions in particular seeing a radical drop in their benchmarks. The following section therefore only examines the period between 2003/04 and 2007/08.

By way of an example for how the location adjusted benchmarks operate, in 2007/08 the University of Kent drew 26.1 percent of its student body from NS-SEC groups 4 to 7, underperforming against a basic benchmark of 29.1 percent based on its subject mix and the age and prior qualifications of its students. However, the location adjusted benchmark was set at 26.3 percent, recognising that the University recruits disproportionately from the affluent southeastern region of England, where there are fewer households from NS-SEC groups 4 to 7 . Once location has been taken into account, it therefore is assessed as recruiting very close to the student mix by socio-economic classification that might be expected, relative to the higher education sector as a whole.

The location adjusted benchmarks therefore provide a yardstick for assessing the performance of individual institutions in relation to the three widening participation indicators. In general, the

\footnotetext{
${ }^{9}$ Full details of how the benchmark figures are calculated can be found at www.hesa.ac.uk/index.php?option=com_content\&task=view\&id=1433\&Itemid=141
} 
Russell Group universities have tended to perform significantly below their benchmarks, in line with on-going concern about equality and fairness (NAO 2008). In the $2007 / 08$ dataset, ten of the fifteen institutions were significantly underperforming relative to their benchmark for entry from state schools and colleges, compared to two significantly exceeding the benchmark and three achieving close to it. For the NS-SEC indicator, five universities were underperforming, none were exceeding and ten were close to the benchmark.

Using the HESA datasets for the five year period prior to 2008/09, the simple arithmetic difference between actual performance and location adjusted benchmark was calculated for each institution, giving a measure of the extent to which they are under-performing (a negative figure) or overperforming (a positive figure). Averages weighted by size of intake were calculated for the Russell Group, Pre-1992 group and Other group of institutions and these are presented in Table 4 and Figures 3 and 4. We find that, on average, the Other group and Pre-1992 group tended to perform slightly above their benchmarks for both indicators, while the Russell Group performed well below its collective benchmark, particularly for admissions from state schools and colleges.

[Table 4 here]

[Figure 3 here]

[Figure 4 here]

Against the schools benchmark, the average performance of Russell Group universities declined from being 5.20 percent below the benchmark in 2003/04 to 6.21 percent below in 2007/08. In contrast, the performance of the Pre-1992 and Other groups remained broadly static. The major change in Russell Group performance coincides directly with the change in student financial support arrangements in $2006 / 07$. This analysis provides specific evidence for a decline in the 
proportion of admissions from widening participation groups into Russell Group universities, relative to the benchmark expectations of institutions with their particular mix of students. At the same time, the performance of both remaining groups has improved to some extent. In terms of performance against the NS-SEC benchmark, there is evidence for a deterioration since a high point in 2004/05 in the Russell Group and Pre-1992 group. In contrast, the average performance of the Other group has been broadly static across the period in question. There is no evidence here for a change in either direction associated with 2006/07.

This evidence notwithstanding, it could be argued that the aggregation and averaging process used in this paper masks a diversity of performances within the Russell Group. For the final piece of analysis, we turn to look at how each of the 15 Russell Group universities progressed relative to their benchmarks taking $2004 / 05$ and $2007 / 08$ as census years, as these avoid the years immediately before and after the financial support changes; the anticipation and then implementation of policy changes could, arguably, provide some anomalous results in the shortterm.

In relation to state schools, six of the fifteen Russell Group universities improved their performance relative to their benchmark, with nine deteriorating. With reference to recruitment from lower socio-economic groups, only two institutions improved, with thirteen declining. While this does speak to diversity within the Russell Group, it remains clear that, with respect to these two benchmarks, the majority of members performed worse in 2007/08 than in 2004/05, before the changes to the student financial support system laid down in the 2004 Higher Education Act were implemented. 


\section{Discussion}

We begin the discussion with a summary of the findings presented above:

1. Across the English higher education sector as a whole, between 2003/04 and 2008/09, there have been modest improvements in the recruitment of young full-time students to first degree courses from state schools and colleges and lower socio-economic groups.

2. Considering the basic proportions, the national improvements in attracting young people from state schools and colleges has been located universally across Russell Group, Pre1992 and Other institutions, albeit at different rates, while the increase in students from lower socio-economic groups has been driven solely by institutions outside the Russell Group.

3. Using the location adjusted benchmarks, the relative performance of the Russell Group universities has declined across the period in question for both indicators, but especially with respect to recruitment from state schools and colleges, where it has fallen rapidly since $2006 / 07$.

4. Looking behind the aggregated figures, we also find that the majority of Russell Group universities declined in terms of their performance relative to benchmark between 2004/05 (before the financial support changes) and 2007/08 (after these changes).

The original purpose of this paper was to consider the impact of the policy changes introduced through the 2004 Higher Education Act on the recruitment of students from non-traditional 
backgrounds, bearing in mind the findings of the Dearing Report (NCIHE 1997). The subsidiary purpose was to consider this question with specific reference to 'top universities', as represented by the Russell Group, where specific concern about fairness of access has been voiced over many years (e.g. NCIHE 1997; Sutton Trust 2000; 2004; NAO 2008; PFAP 2009).

The changes instituted in 2006/07 might be hypothesised to have a number of possible outcomes. A substantial increase in tuition fees, from $£ 1,200$ to $£ 3,000$, might be expected to have a dampening effect on demand for higher education, especially for the most price-sensitive students in less affluent households (Callender and Jackson 2005; Pennell and West 2005). However, the introduction of grants and bursaries for this very group, sometimes of a greater amount that the tuition fee, might be expected to act to ameliorate this or act as an incentive (Pennell and West, 2005), while the other provisions contained within the Access Agreements (e.g. outreach work) were designed to boost demand specifically from under-represented groups.

The findings of this study suggest that, in terms of young entrants to degree courses at least, the radical changes in financial support have not adversely affected participation from the core groups of concern. The overall proportion of students from state schools and colleges and from the lower socio-economic groups has continued to rise, pointing to the success of the Aimhigher programme and other governmental, regional and institutional initiatives. Indeed, 2006/07 was the year of greatest growth in the proportion of students from NS-SEC groups 4 to 7 . Arguably the proportions may have grown faster without the 2006/07 changes, but without a control group, this is impossible to test.

It is also apparent that there is a distinct pattern for the Russell Group universities. In common with the general pattern, they have increased the proportion of their intake from state schools, 
but they continue to lag well behind the Other and Pre-1992 groups in terms of the proportion of their entrants from this educational route. Their rate of growth has also been slower than the national average. The Russell Group universities have not improved their position with respect to students from lower socio-economic groups, as this proportion has remained fixed at around 19 percent. Similarly, the majority of the fifteen institutions are faring worse since the implementation of the 2004 Act relative to the expectations set of them through the location adjusted benchmark.

It would, however, be wrong to assume that these broad trends can be attributed directly to the changes implemented in 2006/07. With one exception (i.e. performance of Russell Group universities against the state school and college benchmark), there are no obvious changes in student profiles that occur precisely at this threshold. This is despite the significant changes to student funding and the new fair access expectations placed on institutions through OFFA. It might be argued that such changes would need time to bed down before the policy objectives are met. However, three years have now passed and there is no sign of the types of shift that were sought by the Act. While the outreach activities contained in Access Agreements might be expected to take time to bear fruit, as we have seen, the radical changes to student funding were predicted to have instant and catastrophic results; these have quite simply not come to pass, in terms of initial entry at least.

It could be hypothesised that the academic years either side of significant change may be unusual. Students have a degree of choice about when they choose to enter higher education, as seen through the increasingly common phenomenon of 'gap years' (Heath 2007). They may, therefore, take an active decision to maximise their financial resources by either delaying (for better state support or the chance to accumulate savings) or bringing forward (to avoid adverse state support 
changes) their entry (Wainwright 2005). No information is available on students who attempt to 'play the system' in this way, but it may go some way to explaining why a single event effect is not found. Another explanation could be that the highly-publicised and controversial changes, which had been in the public arena since the publication of the White Paper in 2003, were actually exerting some effect before their implementation. This could occur through heightened public awareness of the costs of higher education or misunderstanding leading to a belief that changes, especially negative ones, had been enacted earlier than reality. In the absence of repeated studies of student attitudes in this period, it is impossible to assess this possibility directly. There was certainly a sharp jump in public opinion concerning access to higher education and student financial support in 2004, captured in the British Social Attitudes reports (National Centre for Social Research 2010) ${ }^{10}$. However, the most pragmatic interpretation is simply, of course, that the changes implemented by the Act were not a major factor in defining the student entry cohort in this period.

Russell Group universities have been in a position to offer the most generous bursary packages since $2006 / 07$. As they attract relatively few students from under-represented groups, they have positioned themselves in the bursary pseudo-market by focusing on awarding relatively few, but very sizable, bursaries, generally amounting to several thousands of pounds (NAO 2008; McCaig and Adnett 2009). The purpose of this approach has presumably been to answer the Sutton Trust's call (Sutton Trust 2004) to attract a new cadre of very academically able students from under-represented groups who would not otherwise consider applying to the 'top universities'. For example, the University of Manchester Access Agreement opens with a "commitment to being an open, meritocratic institution that pro-actively seeks out people capable of benefiting from

\footnotetext{
${ }^{10}$ Support for widening access to higher education dropped from 50\% in 2003 to $34 \%$ in 2004 ; the lowest level since the question was first asked in 1983. Similarly, the proportion of people believing that higher education should be free for all students dropped from $29 \%$ to $23 \%$. These are the sharpest year-to-year changes in both record sets.
} 
higher education, removes barriers to their participation and in so doing contributes to the expansion of higher education opportunities" (University of Manchester 2009, 1). It is suggested (Callender, Wilkinson and Hopkin, 2009) that students are very cost-sensitive and that the large Russell Group bursaries have been particularly successful in shifting application patterns from students from lower socio-economic groups. This study provides no evidence to support this proposition across the Russell Group as a whole, though it may hold for individual universities within it. A more convincing interpretation is the prediction made by Jones and Thomas, that "the bursary model ... is likely to support exceptional students in elite universities, as opposed the majority of students from under-represented groups in all institutions" $(2005,626)$. Note that the inference is about supporting existing students rather than encouraging additional applications. This may explain Callender, Wilkinson and Hopkin's (2009) finding: students receiving bursaries from Russell Group universities have their decision-making cemented by the financial certainty of the additional money, but they were always the type of student that would make that leap. We will return to this theme later.

An alternative hypothesis is that the Russell Group bursary strategy has helped to ameliorate what could have been a decline in applications from these groups. The overall pattern in widening participation performance over the period in question has been one of relative decline compared to other institutions and, although Russell Group bursaries appear not to have made the distribution of students fairer, they may have helped to avoid it become even less fair than it was.

We need to consider why there has been an apparent policy failure: why are students from lower income households seemingly uninterested in the lucrative sums of money being offered by the 'top universities'? There is plenty of evidence from other research which can drawn upon to address this question. 
For example, we know that students from under-represented groups travel, on average, less far for higher education than other students (UCAS 2008). The reasons behind this geographical immobility are not yet well-understood, but friendship and family ties to the home area (Patiniotis and Holdsworth 2005; Holdsworth 2006; Clayton, Crozier and Reay 2009), caring responsibilities (Evans 2009; Clayton, Crozier and Reay 2009) and financial concerns (Patiniotis and Holdsworth 2005; Davies et al. 2008; Johnson et al. 2009) are likely to be contributory factors. For many such students, this means living in the family home, which is around twice as common among lower socio-economic groups (Patiniotis and Holdsworth 2005; UNITE 2007), while others seek nearby options that permit travel home at weekends. This therefore becomes a limiting factor on choice, reducing the geographical catchment area actively considered by these students. While the Russell Group universities are relatively evenly distributed around England, there are obviously some centres of population that have better access than others. Even where students do move away, financial considerations such as cost of living and access to part-time work are strong considerations (Callender and Jackson 2008).

There are also well-established factors determining institutional preference among non-traditional students. A large corpus of literature in the last ten years (e.g. Thomas 2002; Archer, Hutchings and Ross 2003; Yorke and Thomas 2003; Reay, David and Ball 2005; Gorard et al. 2007; Lehmann 2007; Reay, Crozier and Clayton 2009; 2010) has concluded that the institutional 'habitus' of top universities is alienating and unattractive for many students; "not for people like us". A pervading middle class and elitist ethos acts a deterrent and leads many academically able students to 'choose' not to maximise the status of the institution that they attend. Reay, Crozier and Clayton $(2010,1115)$ go as far as to conclude that working class students need "almost superhuman levels of motivation, resilience and determination" to attend and thrive at elite universities. 
A related feature of the higher education sector in England is that students from minority ethnic communities tend to prefer institutions or locations which already contain a significant proportion of students from their cultural background, or where they have cultural or family links, leading to the concentration of these students in a relatively small number of institutions and effectively acting as another constraint on mobility (Connor et al. 2004; Reay, David and Ball 2005; Clayton, Crozier and Reay 2009). Asian students, in particular, are more likely to choose to live at home, regardless of household income levels (Davies et al. 2008).

It would appear from the evidence presented in this study that the financial incentive of bursaries is not sufficient to overcome the pull of the local and familiar or concerns about the ability to fit in and thrive at Russell Group universities. While the historical record demonstrates that increasing costs of higher education have not acted as an overwhelming disincentive for students from lower socio-economic groups (with evidence of widening participation through the 1990 s and 2000s), so the offer of lucrative bursaries has also failed to shift their application patterns. Students have seemingly proved largely insensitive to financial pushes or pulls. Harrison, Baxter and Hatt (2007), Davies et al. (2008) and Callender, Wilkinson and Hopkin (2009) suggest that this has been due to poor information and misunderstanding, but there is ample evidence discussed above that this, at best, is only a small part of the equation.

This points to a significant failure in public policy around widening participation and fair access. The creation of a financial market for higher education as a tool to achieve these policy aims was a centrepiece objective of the 2004 Higher Education Act. However, no competition in tuition fees has emerged and the market in bursaries appears not to have had anything like the anticipated impact, impacting only a tiny proportion of students; within the group of lower income students, it 
is effectively only geographically-mobile, socially-mobile and academically-excellent students who are able to 'choose' to access significantly higher bursaries. The approach of using competitive markets to stimulate and manage student 'choice' has thus been revealed as naive and paternalistic, based on an assumption that students would ignore social and cultural constraints and sound academic judgement for financial inducements. This failure is evidenced by the fact that access to the 'top universities' has remained high on the political agenda since the Act came into effect and shows no sign of diminishing (NAO 2008; PFAP 2009; Attwood 2010).

Arguably, the failure of the bursary idea has simply allowed 'top universities' to continue with business-as-usual, secure in the knowledge that their Access Agreements give the appearance of offering new incentives to students from under-represented groups, without them being taken up in meaningful numbers. If they were successful in stimulating new demand, these universities would have to either invest a higher total of their additional income in their bursaries or reduce the amounts on offer, decreasing their efficacy.

\section{Conclusion}

This study provides evidence that, in relative terms, access to the 'top universities' in England, represented by the Russell Group, has declined since 2004/05 and that the features of the 2004 Higher Education Act that were intended to make access to these universities fairer have been largely unsuccessful. This is set against a backdrop of modest improvements in the proportion of higher education students drawn from state schools and colleges and lower socio-economic groups which predate the changes. This articulates well with the analysis undertaken by Jones and 
Thomas (2005) five years ago, prior to the implementation of the Act. The 'entrenched privilege' sought out by the 2003 White Paper has evaded the policy ostensibly targeted at it.

Inevitably, this cannot be the final word on the matter. There is still scope for the $2006 / 07$ changes to the student financial support system to bed down into a more mature market, with better targeting, better information and more attractive offers to students. It is, however, difficult to see how the Russell Group universities could meaningfully improve their financial proposition to academically-able students without expending significantly more resources. Based on the data presented in this study, institutionally-specific financial inducements simply do not seem to impact on recruitment patterns to any identifiable degree - though they may have effects elsewhere on retention or quality of the student experience. Similarly, there is no evidence to suggest that there have been fundamental changes in the culture of these institutions since the introduction of the new regulatory framework under OFFA. In fact, this study suggests that 2006/07 changes had a minimal impact on the composition of the student body relative to trends that were already underway. More data will become available in coming years and the analysis in this paper will bear repetition and extension in due course.

On this basis, the pseudo-market in bursaries needs to be questioned. It is debatable whether it provides value-for-money for government, institutions or taxpayers, given the huge sums dispensed and the extensive administrative overhead for all parties. One alternative approach would be to re-organise the system through an expanded, but radically simplified, national bursary system that focused on access to, motivation for and retention within higher education rather than recruitment to specific institutions. There is better evidence to support this approach (e.g. West et al. 2006; Harrison, Baxter and Hatt 2007) than one focused on recruitment. 
This study has focused on aggregated data as a means of examining the policy implications of the 2004 Higher Education Act. Clearly there is significant scope for additional research to better understand why the 2006/07 changes did not positively impact on the fairness of the entry profile more than they appear to have done. This study indirectly suggests that components of individual 'choice' beyond finance continue to exert a greater influence on access to top universities and this needs to be better understood if the next wave of public policy is to succeed in meeting its objectives. 


\section{References:}

Ainley, P. 1994. Degrees of difference: higher education in the 1990s, London: Lawrence and Wishart.

Anderson, C. 1960. Grants to Students (also known as the Anderson Report), London: HMSO.

Archer, L., Hutchings, M. and Ross, A. 2003. Higher Education and social class: issues of exclusion and inclusion, London: RoutledgeFalmer.

Attwood, R. 2010. Mind the gap. Times Higher Education Supplement. $25^{\text {th }}$ February 2010.

Baty, P. 2004. Offa loses teeth in scrap over bill. Times Higher Education Supplement. $4^{\text {th }}$ June 2004.

Callender, C. and J. Jackson. 2005. Does the fear of debt deter students from higher education? Journal of Social Policy 34: 509-540.

Callender, C. and J. Jackson. 2008. Does the fear of debt constrain choice of university and subject of study? Studies in Higher Education 33: 405-429.

Callender, C., D. Wilkinson, and R. Hopkin. 2009. The impact of institutional financial support in England: higher education students' awareness, knowledge and take-up of bursaries and scholarships. Bristol: Office for Fair Access.

Clarke, C. 2004. Letter of instruction to Sir Martin Harris, Director for Fair Access to Higher Education, $25^{\text {th }}$ October 2004. Available online at http://www.dcsf.gov.uk/hegateway/uploads/OFFA\%20final\%20guidance\%20letter\%200ctobe r\%202004.pdf and last accessed 15 ${ }^{\text {th }}$ March 2010.

Clayton, J., G. Crozier, and D. Reay. 2009. Home and away: risk, familiarity and the multiple geographies of the higher education experience. International Studies in Sociology of Education 19: 157-174. 
Connor, H., C. Tyers, T. Modood, and J. Hillage. 2004. Why the difference? A closer look at higher education minority ethnic students and graduates. DfES Research Report 552. Brighton: Institute of Employment Studies.

Davies, P., K. Slack, A. Hughes, J. Mangan, and K. Vigurs. 2008. Knowing where to study? Fees, bursaries and fair access. Stoke-on-Trent: Institute for Educational Policy Research and Institute for Access Studies.

Department for Business, Innovation and Skills [DBIS]. 2009. Full-time young participation by socioeconomic class (FYPSEC), 2009 update. London: DBIS.

Department for Education and Employment [DFEE]. 2000. The excellence challenge. London: DFEE. Department for Education and Skills [DfES]. 2003a. Widening participation in higher education, London: Department for Education and Skills.

Department for Education and Skills [DfES]. 2003b. The future of higher education. Norwich: HMSO.

Evans, S. 2009. In a different place: working class girls and higher education. Sociology 43: 340355.

Gill, J. 2009. NUS calls on 'incompetent head' of Offa to quit, Times Higher Education Supplement, $4^{\text {th }}$ July 2009.

Gorard, S., N. Adnett, H. May, K. Slack, E. Smith, and L. Thomas. 2007. Overcoming the barriers to higher education. Stoke-on-Trent: Trentham Books.

Harris, N. 1991. Social Security, Student Loans and Access to Education. The Modern Law Review 54: $258-270$

Harrison, N., A. Baxter, and S. Hatt. 2007. From opportunity to OFFA: discretionary bursaries and their impact. Journal of Access Policy and Practice 5: 3-21.

Heath, S. 2007. Widening the gap: pre-university gap years and the 'economy of experience'. British Journal of Sociology of Education 28: 89-103. 
Higher Education Statistics Agency [HESA]. 2010. Performance indicators. Available online at www.hesa.ac.uk/index.php/content/category/2/32/141 and last accessed on $15^{\text {th }}$ March 2010.

Holdsworth, C. 2006. 'Don't you think you're missing out, living at home?' Student experiences and residential transitions. The Sociological Review 54: 495-519.

Johnson, C., E. Pollard, W. Hunt, M. Munro, J. Hillage, J. Parfrement and N. Low. 2009. Student income and expenditure survey 2007/08: English-domiciled students. DIUS Research Report 09-05. Brighton: Institute for Employment Studies.

Jones, R. and L. Thomas. 2005. The 2003 UK Government higher education White Paper: a critical assessment of its implications for the access and widening participation agenda. Journal of Education Policy 20: 615-630.

Lehmann, W. 2007. 'I just feel like I don't fit in': The role of habitus in university drop-out decisions. Canadian Journal of Higher Education 37: 89-110.

Lipsett, A. 2005. Top-ups blamed for wane in demand. Times Higher Education Supplement. $16^{\text {th }}$ December 2005.

Lockhart, R. 2009. Independent schools and social mobility, Independent Schools Council Bulletin 25: $10-14$

McCaig, C. and N. Adnett. 2009. English universities, additional fee income and Access Agreements: their impact on widening participation and fair access. British Journal of Educational Studies 57: 18-36.

Modood, T. and M. Shiner. 1994. Ethnic minorities and higher education: Why are there differential rates of entry? London: Policy Studies Institute.

National Centre for Social Research. 2010. British Social Attitudes Information System. Available at www.britsocat.com and last accessed on $15^{\text {th }}$ March 2010. 
National Audit Office [NAO]. 2002. Widening participation in higher education in England. London: The Stationary Office.

National Audit Office [NAO]. 2008. Widening participation in higher education. London: The Stationary Office.

National Committee of Inquiry into Higher Education [NCIHE]. 1997. Higher education in the learning society (known as the Dearing Report). Norwich: HMSO.

NatWest Bank. 2005. Student money matters 2005. London: NatWest Bank.

Office for Fair Access [OFFA]. 2004. Producing Access Agreements: OFFA guidance to institutions. Bristol: OFFA.

Panel on Fair Access to the Professions [PFAP]. 2009. Unleashing aspiration: the final report of the Panel on Fair Access to the Professions (also known as the Milburn Report). London: Cabinet Office.

Patinoitis, J. and C. Holdsworth. 2005. 'Seize that chance!' Leaving home and transitions to higher education. Journal of Youth Studies 8: 81-95.

Pennell, H. and A. West. 2005. The impact of increased fees on participation in higher education in England. Higher Education Quarterly 59: 127-137.

Reay, D., M. David, and S. Ball. 2005. Degrees of choice : class, race, gender and higher education, Stoke-on-Trent: Trentham.

Reay, D., G. Crozier, and J. Clayton. 2009. Strangers in Paradise? Working-class students in elite universities. Sociology 43: 1103-1121.

Reay, D., G. Crozier, and J. Clayton. 2010. 'Fitting In' or 'Standing Out': working-class students in UK higher education. British Educational Research Journal 36: 107-124.

Robbins, L. 1963. Higher education (known as the Robbins Report), Cmnd 2165. London: HMSO. Sanders, C. and A. Goddard. 2003. Rebel MPs steadfast against variable fees. Times Higher Education Supplement. 19 $19^{\text {th }}$ December 2003. 
Schwartz, S. 2004. Fair admissions to higher education: recommendations for good practice, Nottingham: Department for Education and Skills.

Stephens, M. 1990. Students and social security benefits. Journal of Education Policy 5: 77-85. Sutton Trust. 2000. Entry to leading universities, London: Sutton Trust.

Sutton Trust. 2004. The missing 3,000: state school students under-represented at leading universities, London: Sutton Trust.

Thomas, L. 2002. Student retention in higher education: the role of institutional 'habitus'. Journal of Education Policy 17: 423-442.

Thomson, A. 2003. 'Toothless' Offa stokes fees revolt, Times Higher Education Supplement, $11^{\text {th }}$ April 2003.

UCAS. 2008. Distance to higher education, Cheltenham: UCAS.

UNITE. 2007. The student experience report 2007. Bristol: UNITE.

Universities UK. 2005. From the margins to the mainstream: embedding widening participation in higher education, London: Universities UK.

University of Manchester. 2009. Access agreement: updated for AY 2009/10, AY 2010/11, AY 2011/12. Manchester: University of Manchester.

Wainwright, T. 2005. Poor told to snub fees rush. Times Higher Education Supplement. $19^{\text {th }}$ August 2005.

West, A., A. Hind, H. Pennell, C. Emmerson, C. Frayne, S. McNally, and O. Silva. 2006. Evaluation of Aimhigher: Excellence Challenge synthesis report: Surveys of Opportunity Bursary applicants and economic evaluation. DfES Research Report RR709. Slough: NFER.

Yorke, M. and L. Thomas. 2003. Improving the retention of students from lower socio-economic groups, Journal of Higher Education Policy and Management 25: 63-74. 